\title{
Dialogical Theory and Second Language Acquisition
}

\author{
ZHAO Bin \\ Beijing Information Science and Technology University, Beijing, China
}

\begin{abstract}
Dialogical theory provides a new concept for second language acquisition (SLA). SLA should be considered as the process of dynamic interaction between learners' inner ability and the socio-cultural factors. SLA consists of language acquisition and cultural acquisition, which are interdependent and interactive. An efficient way for SLA is the communication between learners' inner ability and the socio-cultural background of foreign language. Both foreign language teachers and learners should be culture-conscious and pay much attention to the cultural differences, which not only provides a more scientific approach for the study of SLA, but also offers a new concept for foreign language teaching.
\end{abstract}

Keywords: dialogical theory, SLA, interaction, cultural acquisition

\section{Introduction of Dialogical Theory}

Dialogical theory was first put forward by Professor Marysia Johnson from Arizona University in 2004. Dialogical theory is based on two theories, one is the theory of Vygotsky and the other is that of Bakhtin. Vygotsky (1978) believes that human's cognitive structure is enriched with the development of social culture and history, and restricted by the social rules. So the high cognitive capability is the result of continuously internalizing the new knowledge from the society. Bakhtin (1980) thinks that language should be considered as utterance but not an abstract system of linguistic forms, such as vocabulary, phonology, and semantics. His theory highlights the social and communicative function of language. By combining the two major theories, Marysia Johnson put forward the famous dialogical theory, which emphasizes the language performance, and considers the second language acquisition (SLA) as an action not a competence. It stresses the dynamic process of SLA. The process of learning a foreign language is actually the dynamic interaction between learner's inner ability and socio-cultural factors (SU, 2006).

Dialogue theory emphasizes the interaction between learner's inner ability and the socio-cultural factors, which not only provides a more scientific approach for the study of SLA, but also offers a new concept for foreign language teaching.

\section{The New Concept for SLA}

Krashen and Long (1982) have argued strongly that SLA is dependent on the availability of comprehensible input before the learner's internal processing mechanism can work, that is to say the input must consist of " $\mathrm{i}+1$ ", if we consider the learner's innate ability as “i”. Krashen (1982) writes:

ZHAO Bin, associate professor, master, Foreign Studies College, Beijing Information Science and Technology University. 
...a necessary (but not sufficient) condition to move from stage " $\mathrm{i}$ ” to stage " $\mathrm{i}+1$ " is that the acquirer understands input that contains " $\mathrm{i}+1$ ", where "understand" means that the acquirer is focused on the meaning and not the form of the message. (p. 21)

And also Krashen (1982, p. 78) points out four premises of language input: (1) comprehensibility, (2) interesting and relevant, (3) not grammatically sequenced, and (4) quantity. In terms of the fourth premise, he means that the learner must receive ample knowledge about the foreign language. In the author's opinion, the quality of the received ample knowledge should also be defined. The knowledge should not only be of a little higher grade but also much about the culture of foreign language. So the "1" can be considered as the cultural input. Culture learning is very important for foreign language learning. The famous linguist Lado thinks that learners cannot actually acquire a language if they do not know the model and principles of that culture. Professor DENG Yan-chang, a famous English expert in China, once pointed out that it is a must to learn the relevant culture for foreign language learners (as cited in F. LIU, 2006, p. 119).

\section{Language Acquisition and Cultural Acquisition}

\section{The Contrast Between Language Acquisition and Cultural Acquisition}

Similarity. Both of them have the internalization of systematic knowledge. Different languages of different countries or nations have different systems, such as vocabulary, pronunciation, grammar, meaning, etc.. And different regions also have different cultural systems, such as Chinese culture, Japanese culture, American culture, etc.. Language acquisition and cultural acquisition are interdependent and interactive.

Difference. It is more difficult to acquire culture, since culture is invisible, just as what E. Hall (1973) says in The Silent Language: "Culture can be classified into two categories: visible culture and invisible culture. The former can be described, while the latter cannot be recognized even by specially trained observers".

The invisibility of culture is the major obstacle in cultural acquisition, while the objectives of language acquisition are usually visible. Cultural acquisition always covers a lot of fields, ranging from the daily life to human's inner psychological world. Language acquisition, at present, is considered as the acquisition of skills of listening, speaking, reading, writing, and translation.

\section{The Relationship Between Language Acquisition and Cultural Acquisition}

Language acquisition and cultural acquisition are interdependent and interactive. Moran (2004) points out that cultural acquisition should be a conscious, aim-oriented and full of experience cycle. In this cycle, there are two important parts: cultural experience and cultural reflection.

Cultural experience means getting access to the living style of native speakers and knowing much about their culture, in order to inspire learners to take part in the culture physically, mentally, and psychologically. Cultural experience includes: understanding cultural information, feeling the cultural activity, and getting to know cultural beliefs (SU, 2006, p. 124), that is to say, comprehending and receiving the cultural knowledge from the society of foreign language, understanding the customs and traditions related to cultural activities, and getting access to the invisible culture, such as values, beliefs, attitude, concept, etc.

Cultural reflection means that learners analyze what they have heard, seen and read, make comparison of the difference between first language and second language and internalize what they want to know, forming the cultural self-awareness (SU, 2006, p. 124). 
So we can conclude that cultural experience is the premise for cultural awareness. Cultural awareness is just like a filter for cultural experience, learners selecting what they want to know and also choosing what kinds of cultural experience they want to be exposed to. In turn, cultural awareness will make some change to cultural experience.

The dynamic interaction is the same with the relationship between language learning and language awareness. Language learning and language awareness will respectively affect and be affected by cultural experience and cultural awareness, according to Byram (1998).

\section{The Role of a Language Teacher}

A language teacher is not only the impresario of a certain linguistic performance, but as the catalyst for an ever-widening critical cultural competence. That is to say, a language teacher is not merely a language knowledge instructor, but more importantly a culture disseminator. So in the first place, the teachers should be sentimental to the cultural background related to the language and try their best to make themselves full of language culture, the more, the better. Comprehensible input is the source of new knowledge and achieved by the communication between the learner's innate ability and certain extra linguistic context: The extra linguistic context may include the cultural background of a foreign language, customs, values and beliefs of its native speakers, and even its political and social systems. Since most of the Chinese students have no opportunity to go abroad, they cannot get access to the real extra linguistic environment. Secondly, foreign language teachers are required to create an extra linguistic environment similar to the real one, the more similar, the better.

\section{How to Create a Real Extra Linguistic Context in Classroom?}

\section{A Comparison of Natural and Classroom Language Environments}

There is often a general assumption that natural and classroom settings differ substantially, particularly when the classroom environment involves the formal teaching of a second language. Corder (1976), for instance, writes:

...learners do not use their interlanguage very often in the classroom for what we may call "normal" or "authentic" communicative purposes. The greater part of interlanguage data in the classroom is produced as a result of formal exercises and bears the same relation to the spontaneous communicative use of language as the practicing of tennis strokes does to playing tennis. (p. 68)

Corder is referring to the output of the learner, but his comments might be equally valid where the input is concerned (Ellis, 1985, p. 150). The differences between natural and classroom communication are also reflected in different motivational orientations. MacNamara (1973) suggests that the kind of motivation which occurs in classroom setting is completely different from that found in "street" settings. "In classrooms, the input is of a reduced variety and affords limited opportunities for hypothesis formation and testing” (D’Anglejan, 1978, p. 50).

Although there are clear and obvious differences between natural and classroom environments, it would be wrong to overemphasize these differences.

Rather than treat natural and classroom environments as opposites, it would be more accurate to see them as providing the same discourse types in different degrees. That is, the same kind of interactions can take place in both, but because of basic arrangements, some types of these interactions are more frequent in one setting, and other types in the other setting. (Ellis, 1985, p. 150) 
As Krashen (1982) comments, classrooms can afford opportunities for genuine communicative exchanges, while in natural settings learners can engage in formal study, or, as Corder puts it, the "practising of tennis strokes”. In classroom, learners have limited opportunities to get access to the culture of foreign language, while in natural environment, learners can get the tracks of foreign language culture in the talk with native speakers. In order to promote the efficiency for SLA, teachers should try to create an immersion classroom, and bring in more culture of foreign language to create the strongest resemblance to natural settings.

\section{Strengthening Learners' Cultural Consciousness}

Teachers should strengthen learners' cultural consciousness by making them believe that a foreign language can be learned well only if combined with its relevant culture. Language and culture cannot be separated by force, since they are integrated. Learning a foreign language not only refers to learning its vocabulary, grammar, sentence structure, etc., but the most important is to acquire its culture. Language has social and communicative functions, only a good communicator can be considered as a really nice language learner. Particularly, in modern society, with the advancement of globalization, cross-cultural communication becomes an important and integrated part of human life. So foreign language learners should pay much attention to learning its culture and the foreign language teachers should give priority to teaching culture.

\section{Explaining Confusing Words or Phrases by Cultural Analysis}

Teachers should explain confusing words or phrases by resorting to their origins, namely, seeking out the background in which these words or phrases came to exist. In the course of learning English, we may encounter many idioms, slang, and phrases from the Bible, and often find them confusing and incomprehensible. Since these phrases often contain profound cultural and social meanings, learners usually find that they cannot figure out the exact meaning even if they know every word in the phrase.

For example, "to touch all bases" means to do what is necessary to complete an activity. The expression is used in business and politics. No business deal or a political campaign is really complete until you discuss all the issues involved or as it is said until you "touch all bases". The phrase "to touch all the bases" comes from a sport of baseball. There are four bases in baseball, first, second, third, and the fourth, and players are required to touch all the bases before they hit the ball. So if the player hits the ball and fails to touch all the bases, the point will not be counted. "A battle axe" now is used to describe a woman or man as a strong, shark competitor in business, because almost 2,000 years ago, the Gaux used battle axes. The axes were very strong and shark and they could cut through the heavy metal armors that Gaux wore to protect themselves. The battle axes permitted the Gaux to win battles against Romans. The Romans at that time were feared fighters.

In American movies, we often encounter many very native expressions. We would feel puzzled if we do not know the cultural background related to these expressions. "Down in the dumps" is used to describe people who are sad. Word expert Charol Funk says people had been feeling down in the dumps for more than 400 years. Sir Thomas More used the expression in 1534. He wrote: “Our poor family has fallen in such dumps”. The word "dumps" may come from the languages of Denmark and Norway. The word means to fall suddenly. Americans borrowed this saying. And over the years, it has become a popular way of expressing sadness.

"Get your act together" is borrowed from the theatre or movie industry. When one of the actors was nervous and made a lot of mistakes, the directors often said "calm down now, get your act together”. So the phrase is now 
used in business to mean developing a calm and orderly plan of action. "Cut to the chase" means to stop spending so much time on details or unimportant material, hurry and get to the good part. Naturally this saying was started by people who make movies. Hollywood movie producers believe that most Americans want to see action movies. Many of their movies show scenes in which the actors chase each other in cars or in airplanes or on foot. "Cut" is the director's word for stop. The director means to stop filming to leave some material and get to the chase scene now.

All of the phrases are full of cultural background, some from historical events and some from native speakers' daily life. The background is of great interest, which would help learners comprehend and memorize the phrases.

Apart from teachers' introduction about cultural background, encouraging learners to accumulate and sort out the background materials and then organizing a report to be delivered in the classroom is another effective and interesting way to inspire students' aspiration for cultural learning.

\section{Designing Target-Based Group Work Similar to the Real Life of Native Speakers}

Learners are given some situations from real life, such as going to see the doctor, shopping in the supermarket, getting your bicycle repaired, etc.. The more close to the real life, the better are the situations. Since these situations are simple and close to daily life, learners can create the lyrics according to their own experience. After students' demonstration, teachers should show them the real life of native speakers to make a comparison between the students' lyrics and body languages with those of native speakers. This comparison is very important and necessary. Learners can get to know more knowledge related to the culture of foreign language.

\section{Multimedia Use and Cultural Cases Study}

The use of multimedia and TV plays an important role in the cultural learning. It is an easier way of getting access to the real life of native speakers. Movies and TV always show us a lot of things, ranging from the daily life to the political election. So an American movie lover usually knows much about American culture. Teachers are required to recommend good movies or TV shows for learners to know the culture of foreign language.

Sometimes to highlight the cultural difference between first language and second language, teachers would deliver a systematic report to analysize cultural cases. Cases studies are usually impressive and make learners have more clear ideas about foreign language culture, which would help promote the cultural acquisition.

\section{Conclusion}

SLA is a complex process consisting of language acquisition and cultural acquisition, which are interdependent and interactive. An efficient way for SLA is the communication between learners' inner ability and the socio-cultural background of foreign language. Both foreign language teachers and learners should be culture-conscious and pay much attention to the cultural differences.

\section{References}

Bakhtin, M. M. (1980). Speech genres and other late essays. Austin, Texas: University of Austin.

Byram, M. (1998). Cultural studies in foreign language education. Clevedon, UK: Multilingual Matters Ltd..

Corder, S. (1976). The study of interlanguage. In Proceedings of the Fourth International Congress in Applied Linguistics. Munich: Hochschulverlag.

D’Anglejan, A. (1978). Language learning in and out of classrooms. Beijing: Foreign Language Teaching and Research Press. 
Ellis, R. (1985). Understanding second language acquisition. Shanghai: Shanghai Foreign Education Press.

Hall, E. T. (1973). The silent language. New York: Anchor.

Johnson, M. (2004). A philosophy of second language acquisition. New Haven: Yale University Press.

Krashen, S. (1982). Formal and informal linguistic environments in language acquisition and language learning. TESOL Quarterly, 10, 40.

Krashen, S., \& Long, M. H. (1982). Principles and practice in second language acquisition. Oxford: Pergamon Press.

LIU, C., \& XU, L. J. (2006). Foreign language learning and acquisition of alien culture. Journal of Sichuan University of Science and Engineering, 10, 25.

LIU, F. ( 2006). Language acquisition and cultural acquisition. Journal of Yili Teachers, 8, 23.

MacNamara, J. (1973). Nurseries, streets and classrooms: some comparisons and deductions. Modern Language Journal, 57, $250-4$. Moran, P. R. (2004). Teaching culture: Perspectives in practice. Beijing: Foreign Language Teaching and Research Press.

SU, W. J. (2006). Culture acquisition in two language acquisition. Journal of Qiqihar University, 5, 33.

Vygotsky, L. S. (1978). Mind in society. Cambridge: MIT Press. 